\title{
Hétérotrophie algale : effets de la gentamycine et de la cycloheximide sur les activités hétérotrophes et photosynthétiques des bacteries et des algues Algal heterotrophy: effects of gentamycin and cycloheximide on bacteriat and algal heterotrophic and photosynthetic activities
}

\author{
A. Rachiq, C. Amblard et G. Bourdier
}

Volume 4, numéro 3, 1991

URI : https://id.erudit.org/iderudit/705104ar

DOI : https://doi.org/10.7202/705104ar

Aller au sommaire du numéro

\section{Éditeur(s)}

Université du Québec - INRS-Eau, Terre et Environnement (INRS-ETE)

ISSN

0992-7158 (imprimé)

1718-8598 (numérique)

Découvrir la revue

Citer cet article

Rachiq, A., Amblard, C. \& Bourdier, G. (1991). Hétérotrophie algale : effets de la gentamycine et de la cycloheximide sur les activités hétérotrophes et photosynthétiques des bacteries et des algues. Revue des sciences de l'eau / Journal of Water Science, 4(3), 343-361. https://doi.org/10.7202/705104ar

\section{Résumé de l'article}

Afin de tenter de déterminer les parts respectives des activités bactérienne et algale, nous avons testé d'une part, l'action d'une substance antibactérienne (la gentamycine), et d'autre part, l'action d'un inhibiteur métabolique des cellules eucaryotes (la cycloheximide) sur des cultures d'algues et de bactéries et sur des échantillons provenant du milieu naturel et soumis à des filtrations différentielles. Les effets de ces inhibiteurs ont été testés au niveau des activités hétérotrophe et photosynthétique globales, mais également au niveau de l'incorporation des marqueurs radioactifs lors de la synthèse des macromolécules et des composés de faible poids moléculaire.

Les résultats obtenus laissent apparaître que l'inhibition de l'activité bactérienne par la gentamyclne est significative mais non complète (pourcentage d'inhibition moyen $=67 \%$ ). De plus, l'efficacité de la gentamycine augmente avec la durée d'incubation. Par ailleurs, les effets secondaires de la gentamycine sur les activités hétérotrophe et photosynthétique d'une culture de Melosira italica subsp. subarctica sont acceptables seulement pour des incubations de courte durée ( $<4$ heures).

En revanche, l'emploi de la cycloheximide s'est révélé sans aucun effet significatif sur les activités photosynthétique et hérérotrophe de la culture de Melosira, même après $24 \mathrm{~h}$ d'incubation.

A partir des échantillons prélevés en milieu naturel, l'emploi de la gentamycine a permis de réduire l'interférence bactérienne dans les mesures d'activité hétérotrophe algale. Enfin, nous avons pu constater que la gentamycine modifie l'allocation des marqueurs radioactifs dans les macromolécules. 


\title{
Hétérotrophie algale : effets de la gentamycine et de la cycloheximide sur les activités hétérotrophes et photosynthétiques des bacteries et des algues*
}

\author{
Algal heterotrophy : \\ effects of gentamycin and cycloheximide \\ on bacterial and algal heterotrophic \\ and photosynthetic activities
}

\section{S. RACHIQ1', C. AMBLARD1, G. BOURDIER 1}

Reçu le 5 juillet 1990, accepté pour publication le 28 janvier 1991 **.

RÉSUMÉ

Afin de tenter de déterminer les parts respectives des activités bactérienne et algale, nous avons testé d'une part, l'action d'une substance antibactérienne (la gentamycine), et d'autre part, l'action d'un inhibileur métabolique des cellules eucaryotes (la cycloheximide) sur des cultures d'algues et de bactéries et sur des échantillons provenant du milieu naturel et soumis à des filtrations diftérentielles. Les effets de ces inhibiteurs ont été testés au niveau des activités hétérotrophe et photosynthétique globales, mais également au niveau de l'incorporation des marqueurs radioactifs lors de la synthèse des macromolécules et des composés de faible poids moléculaire.

Les résultats obtenus laissent apparaître que l'inhibition de l'activité bactérienne par la gentamycine est significative mais non complète (pourcentage d'inhibition moyen $=67 \%$ ). De plus, l'efficacite de la gentamycine augmente avec la durée d'incubation. Par ailleurs, les effets secondaires de la gentamycine sur les activités hétérotrophe et photosynthétique d'une culture de Melosira lialica subsp. subarctica sont acceptables seulement pour des incubations de courte durée (< 4 heures).

En revanche, l'emploi de la cycloheximide s'est révélé sans aucun effet significatif sur les activités photosynthélique et hérérotrophe de la culture de Melosira, même après 24 h d'incubation.

1. Laboratoire de Zoologie-Protistologie, URA CNRS 138, Universite Blaise Pascal Clermont-Ferrand II, Les Cézzaux, 63177 Aubière cedex.

- Communication présentée au 34e Congrès de l'Association Française de Limnologie, Metz-Nancy, 29-31 mai 1990.

* Les commentaires seront reçus jusqu'au 30 mars 1992. 
A partir des échantillons prélevés en milieu naturel, I'emplol de la gentamycine a permis de réduire l'interférence bactérienne dans les mesures d'activité hétérotrophe algale. Enfin, nous avons pu constater que la gentamycine modifie l'allocation des marqueurs radioactifs dans les macromolécules.

Mots clés : Algue, bactérie, gentamycine, hétérotrophie, activité photosynthetique.

The ability of many planktonic algae to use particulate and/or dissolved organic carbon directly by phagotrophy or osmotrophy in laboratory cultures is well documented (OROOP, 1974 ; MEILSON and LEWIM, 1974 ; HELLEBUST and LEWIN, 1977 ; BIRD and KALFF, 1986). In axenic cultures, numerous microalgae grow in the dark with micromolar concentrations of diverse organic nutrients as their sole sources of carbon and energy (RIVKIN and PUT, 1987). However, to demonstrate algal heterotrophy in the field, it is necessary to differentiate between bacterial and algal activities. In the course of this study, we tested the effect of an antibacterial substance (gentamycin) and of a metabolic inhibitor of eukaryotic celis (cycloheximide) on algal and bacterial cultures, and also on lake water samples submitted to differential filtration. The effect of these inhibitors was tested both at the overal heterotrophic and photosynthetic activities level and the level of the incorporation of radiolabeled tracers in macromolecules and low molecular weight compounds.

Gentamycin was tested on bacteria and on an axenic culture of the diatom Melosira italica subsp. subartica, the dominant species of the spring phytoplanktonic bloom of many temperate lakes. Bacterial culture was obtained by filtration of a senescent culture of Melosira through a $0.45 \mu \mathrm{m}$ pore-size mem. brane. During exponential growth, gentamycin $\left(40 \mu \mathrm{g} \cdot \mathrm{ml}^{-1}\right)$ was added to different flasks containing $100 \mathrm{ml}$ of culture, $30 \mathrm{mn}$ after gentamycin addition, $\mathrm{Na} \mathrm{H}^{14} \mathrm{CO}_{3}(12 \mu \mathrm{Ci} / 100 \mathrm{ml})$ was introduced into the flasks. In each case, two replicates were incubated in the light and two in the dark for $0.5,1,2,4,6,8$, 12 and 24 hours. After incubation, aliquots were collected on a filtration membrane $(0.45 \mu \mathrm{m})$ and the radioactivity was measured using an LKB liquid scintillation counter to estimate photosynthetic activity. Incorporation of inorganic carbon into macromolecules was measured using the procedure described by LAHCELOT and MATHOT (1985), which allows the separation of lipids, polysaccharides, proteins and low molecular weight compounds (e.g. amino acids, organic acids and monosaccharides) by virtue of their relative solubilities in different extraction solvents :

- lipids were extracted with a $2 / 1$ (v/v) chloroform-methanol mixture ;

- low molecular weight compounds were extracted with hot ethanol;

- proteins were precipated with TCA at elevated temperature; this also separated them from polysaccharides. Nucleic acids were recovered with the polysaccharides iraction. Results are given as a percentage of total radioactivity. The same method, as that described for photosynthetic incorporation, was used to measure incorporation of glucose ${ }^{3} \mathrm{H}$ (19 nmoles..$\left.^{-1}\right)$ and for the allocation of radioactive marker in macromolecules. To assess the elfect of cycloheximide, the same procedure as that described for gentamycin was used. Howewer, due to the lack of references, three cycloheximide concentrations were tested $=50,100$ and $150 \mu \mathrm{g} \cdot \mathrm{mt}^{-1}$, and aliquots were collected on a $0.2 \mu \mathrm{m}$ pore-size membrane.

Field samples were taken in Lake Pavin, an oligomesotrophic French lake, during the sedimentation of Melosira italica subsp. subarctica, the prevailing species of the spring bloom. The effects of gentamycin on photosynthetic and heterotrophic incorporations were tested with the same procedure as that described for cultures. However, radioactivity was measured for different size 
fractions : $0.2-0.45 \mu \mathrm{m}, 0.45-5 \mu \mathrm{m}$ and $5-160 \mu \mathrm{m}$, after incubations for $0.5,1$, $3,6,12$ and 24 hours. Phytoplanktonic celis were counted on a Wild M40 inverted microscope and bacterial enumeration was realized in epiffuorescence microscopy after staining with acridine orange (HOBBIE et al., 1977).

Results show that gentamycin used at $\mathbf{4 0} \mu \mathrm{g} \cdot \mathrm{ml}^{-1}$ inhibits significantly but not completely the activity of the bacterial culture (mean inhibition percent = $67 \%$ ). Gentamycin efficiency increases with incubation time, the inhibition reaching $81 \%$ after $24 \mathrm{~h}$. At the same time, the secondary effects of gentamycin on heterotrophic and photosynthetic activities of Melosira italica subsp. subarctica in culture were only tolerable with short incubation times $(<4 \mathrm{~h})$, when the percents of inhibition were respectively 13.6 and $12.2 \%$. On the other hand, cycloheximide produced no significant effect on photosynthetic and heterotrophic activities of Melosira italica in culture, the percent of inhibition always remaining below $6.5 \%$.

The use of gentamycin in natural samples reduced bacterial interference with algal heterotrophic activity measurements. The percent of inhibition caused by gentamycin was high $(<76 \%)$ in the small-size fraction where the bacterial biomass predominate on the phytoplanktonic one.

Lastly, in all samples, we could demonstrate that gentamycin modifies the allocation of inorganic carbon and radioactivity in macromolecules. The incorporation in proteins is significanily reduced essentially to benefit of the incorporation in low molecular weight compounds.

Key-words : Algae, bacteria, gentamycin, heterotrophy, photosynthetic activity.

\section{1 - INTRODUCTION}

Le phytoplancton a été trop longtemps considéré seulement comme une communauté strictement autotrophe du point de vue de ses besoins en carbone. Des espèces algales sont, en effet, capables d'assimiler directement le carbone organique, soit dissous par osmotrophie (DROOP, 1974 ; NEILSON et LEWIN, 1974), soit particulaire par phagotrophie (BIRD et KALFF, 1986). La mise en évidence de l'activité hétérotrophe algale en culture axénique est bien documentée depuis deux décennies (DROOP, 1974 ; NEILSON et LEWIN, 1974 ; HELLEBUST et LEWIN, 1977). II ressort de ces travaux qu'un nombre appréciable d'algues peuvent assimiler et utiliser pour leur croissance, des composés organiques dissous comme source de carbone et d'énergie, à la fois à la lumière (photohétérotrophie) et à l'obscurité (chémohétérotrophie).

En milieu naturel, il a pu être démontré que l'assimilation hétérotrophe est, pour les algues, une possibilité supplémentaire de fixation de carbone susceptible de jouer un rôle déterminant dans la survie des espèces et dans les interactions compétitives, même si la fixation du carbone inorganique par voie photosynthétique reste généralement prépondérante (Mc KINLEY et WETZEL, 1979 ; ELLIS et STANFORD, 1982 ; WETZEL, 1983 ; RIVKIN et PUTT, 1987 ; PAERL, 1988). Naturellement, les potentialités hétérotrophes algales 
paraissent plus importantes dans les milieux aquatiques riches en carbone organique dissous et/ou limités en énergie lumineuse (AMBLARD et al., 1990 ; Amblard, sous presse). Cependant, l'expérimentateur se heurte fréquemment à plusieurs difficultés d'ordre méthodologique. Tout d'abord, il est souvent difficile de faire les parts respectives des activités bactérienne et algale. II a d'ailleurs été longtemps admis que les algues n'étaient pas compétitives par rapport aux bactéries pour la prise de substrats organiques en milieu naturel (WRIGHT et HOBBIE, 1966 ; MUNRO et BROCK, 1968 ; HELLEBUST, 1970 ; LEWIN et HELLEBUST, 1976). Aussi, généralement, attribuait-on, en priorité, les phénomènes de photohétérotrophie aux algues et les activités chémohétérotrophes aux bactéries (Mc KINLEY, 1977). Cependant, les bactéries photosynthétiques sont capables, d'une part, de présenter un métabolisme photohétérotrophe, mais sous conditions anaérobies (STANIER, 1973), et d'autre part, des espèces phytoplanctoniques sont susceptibles d'assimiler par chémohétérotrophie des substrats organiques aux concentrations rencontrées en milieu naturel (ELLIS et STANFORD, 1982 ; MOLL, 1984 ; BOURDIER et al., 1989).

Le fractionnement par filtration différentielle en fonction de la taille (SHELDON et STUCLIFFE, 1969 ; SHELDON, 1972 ; HOPPE, 1976) ne permet pas toujours une distinction claire entre activité algale et activité bactérienne en raison de la présence de bactéries fixées sur des particules de grande taille, ce qui rend cette procédure inopérante sous certaines conditions. L'inhibition de l'activité hétérotrophe bactérienne par des substances antibiotiques a été assez fréquemment réalisée (BERMAN, 1975 ; ITURRIAGA et ZSOLNAY, 1981 ; NEWELL et al., 1983 ; FUHRMAN et Mc MANUS, 1984). Cependant, de nombreuses incertitudes demeurent quant à l'efficacité de ces substances et à leurs effets secondaires sur les cellules eucaryotes.

En conséquence, l'objectif de cette étude, a été de tester d'une part, l'action d'une substance antibactérienne (la gentamycine) et d'autre part, l'action d'un inhibiteur métabolique des cellules eucaryotes (la cycloheximide), sur des cultures d'algues et de bactéries et sur des échantilions provenant du milieu naturel, afin d'essayer de déterminer les parts respectives des activités bactérienne et algale. Les effets de ces inhibiteurs ont été testés au niveau des activités hétérotrophe et photosynthétique globales, mais également au niveau de lincorporation des marqueurs radioactifs dans les macromolécules et les composés de faible poids moléculaire. En effet, lutilisation rationnelle de substances antibactériennes nécessite de vérifier limportance des effets secondaires éventuels de ces inhibiteurs sur la synthèse des produits terminaux de la photosynthèse.

\section{2 - MÉTHODOLOGIE}

\subsection{Expériences réalisées sur des cultures}

Les études ont été menées sur une culture axénique de Melosira italica subsp. subarctica (Diatomée centrique), espèce très fréquente dans les 
communautés phytoplantoniques lacustres, et sur une culture de bactéries obtenue par récupération du filtrat (filtration sur filtre Millipore $0,45 \mu \mathrm{m}$ ) d"une culture contaminée de Melosira italica subsp. subarctica en phase de sénescence. Ces deux cultures ont été réalisées sur un milieu minéral non renouvelé, dans une chambre climatisée $\left(19^{\circ} \mathrm{C} \pm 1\right)$ et sous un éclairage nycthéméral (lumière $16 \mathrm{~h} /$ obscurité $8 \mathrm{~h}$, lumière blanche, intensité lumineuse $\left.\approx 100 \mu \mathrm{E} \cdot \mathrm{m}^{-2} \cdot \mathrm{s}^{-1}\right)$.

- Les effets de la gentamycine sur la culture de Melosira en phase de croissance exponentielle ont été étudiés à partir d'une série de 4 flacons de culture $(100 \mathrm{ml})$ ( 2 flacons clairs +2 flacons obscurs). Dans deux flacons ( 1 clair +1 obscur) est ajoutée de la gentamycine à une concentration de $40 \mu \mathrm{g} \cdot \mathrm{ml}^{-1}$ (ITURRIAGA et ZSOLNAY, 1981). Trente minutes après l'addition de gentamycine, les substrats radioactifs destinés à la mesure des activités photosynthétique $\left(\mathrm{NaH}^{14} \mathrm{CO}_{3}\right.$ à raison de $\left.12 \mu \mathrm{Ci} / 100 \mathrm{ml}\right)$ et hétérotrophe (glucose ${ }^{-3} \mathrm{H}$ a raison de 19 nmoles/litre) sont introduits dans les flacons de culture. Des flacons sans gentamycine servent de témoins. L'abondance cellulaire de la culture de Melosira est de $3 \times 10^{4}$ cellules. $\mathrm{ml}^{-1}$ au début des incubations. Par la suite, aux temps $0,5,1,2,4,6,8,12$ et $24 \mathrm{~h}, 11 \mathrm{ml}$ de culture sont prélevés stérilement puis filtrés sur membrane Millipore de porosité $0,45 \mu \mathrm{m}$. La radioactivité retenue sur les filtres destinés à calculer les activités photosynthétique et hétérotrophe est comptée à l'aide d'un compteur à scintillation liquide. Afin de déterminer l'allocation du carbone inorganique dans les macromolécules après activité photosynthétique, nous avons suivi le protocole décrit par LANCELOT et MATHOT (1985) qui permet d'isoler, à partir de leur solubilité relative dans différents extractants, les lipides, les polysaccharides, les protéines et les composés de faible poids moléculaire (acides aminés, acides organiques, monosaccharides, ...) :

- les lipides sont extraits par le mélange chloroforme - méthanol 2/1 $(v / v)$;

- les composés de faible poids moléculaire sont extraits par l'éthanol à chaud ;

- les protéines sont précipitées par le TCA à chaud, et de ce fait, séparées des polysaccharides (les acides nucléiques sont recueillis avec la fraction polysaccharidique).

La radioactivité associée à chacune des fractions est comme précédemment déterminée au compteur à scintillation liquide. Les résultats sont présentés en pourcentages de la radioactivité totale. L'allocation de la radioctivité dans les macromolécules après incubation en présence de glucose a été mesurée selon le même protocole.

Grâce à l'utilisation d'échantillons préfixés aux formol $(2 \%)$, nous avons pu vérifier que les phénomènes d'absorption représentent toujours moins de $2 \%$ de la radioactivité totale.

- Sur la culture de bactéries, la même procédure a été adoptée pour connaître l'action de la gentamycine (concentration $40 \mu \mathrm{g} . \mathrm{m}^{-1}$ ) sur l'incorporation du glucose $-3 \mathrm{H}$. Cependant, les filtrations sont réalisées sur filtres Sartorius de porosité $0,2 \mu \mathrm{m}$ et seule l'activité hétérotrophe globale a été mesurée. L'abondance de la culture de bactéries au début des incubations était de $1,2 \times 10^{7}$ cellules. $\mathrm{ml}^{-1}$. 
L'effet de la cycloheximide sur les cultures d'algues et de bactéries a été étudié dans les mêmes conditions. Cependant, devant la quasi-absence de référence concernant les conditions d'utilisation de cet inhibiteur dans le cas des microalgues, trois concentrations ont été testées : 50,100 et $150 \mu \mathrm{g} \cdot \mathrm{ml}^{-1}$. Au début des incubations, les abondances bactérienne et algale étaient respectivement de $1,2 \times 10^{7}$ et $3,3 \times 10^{4}$ cellules. $\mathrm{ml}^{-1}$.

\subsection{Expériences réalisées à partir de prélèvements effectués en milieu naturel}

Des prélèvements ont été effectués au lac Pavin, lac oligo-mésotrophe du Massif Central français, lors de la phase de sédimentation de l'espèce dominante du plancton printanier (Melosira italica subsp. subarctica). L'eau a été prélevée aux profondeurs 5 et $50 \mathrm{~m}$ puis préfiltrée sur un tamis d'ouverture de maille de $160 \mu \mathrm{m}$ afin d'éliminer la plus grande partie de zooplancton. Les prélèvements provenant de la profondeur $5 \mathrm{~m}$ ont été placés en chambre climatisée à $13^{\circ} \mathrm{C}$ et sous éclairage constant (lumière blanche, $\approx 100 \mu \mathrm{E} \cdot \mathrm{m}^{-2} \cdot \mathrm{s}^{-1}$ ) alors que ceux du niveau $50 \mathrm{~m}$ ont été mis à l'obscurité et à $4{ }^{\circ} \mathrm{C}$, conditions proches de celles rencontrées à ces profondeurs dans ce lac. L'effet de la gentamycine, ajoutée à une concentration de $40 \mu \mathrm{g} \cdot \mathrm{ml}^{-1}$, a été suivi comme précédemment grâce aux précurseurs radioactifs destinés à la mesure des activités photosynthétique $\left(\mathrm{NaH}^{14} \mathrm{CO}_{3}\right.$, à raison de $12 \mu \mathrm{Ci} /$ $100 \mathrm{ml}$ ) et hétérotrophe (glucose ${ }^{-3} \mathrm{H}$, à raison de $19 \mathrm{nmoles} / \mathrm{litre}$ ). $5 \mathrm{ml}$ pour la mesure des activités globales (classes de taille : 0,2-0,45 $\mu \mathrm{m}, 0,45-5 \mu \mathrm{m}$ et $5-160 \mu \mathrm{m}$ ) et $50 \mathrm{ml}$ pour l'incorporation des marqueurs dans les macromolécules (classe de taille 5-160 $\mu \mathrm{m}$ seulement) ont été prélevés aux temps 0,5 , $1,3,6,12$ et $24 \mathrm{~h}$.

Enfin, les dénombrements cellulaires d'algues sont réalisés au microscope inversé WILD M40, selon la méthode d'UTERMOHL (1958) modifiée par LEGENDRE et WATT (1971-1972). Les dénombrements bactériens sont effectués en microscopie à épifluorescence après coloration par l'acridine orange (HOBBiE et al., 1977).

\section{3 - RÉSULTATS}

\subsection{Effets de la gentamycine sur les activités hétérotrophes et photosynthétiques globales des cultures d'algues et de bactéries}

Calculée à partir de lassimilation de glucose ${ }^{-3} \mathrm{H}$, l'activité hétérotrophe bactérienne est réduite en présence de gentamycine (fig. 1). Le pourcentage d'inhibition est en moyenne de $66,6 \%$, toutes durées d'incubation confondues. Cependant, pour des incubations inférieures ou égales à $4 \mathrm{~h}$, le pourcentage d'inhibition n'est en moyenne que $39,0 \%$ alors que pour les incuba- 
tions dont la durée est supérieure à $4 \mathrm{~h}$, le pourcentage moyen d'inhitition atteint $74,8 \%$, et il est de $81,4 \%$ pour des incubations de $24 \mathrm{~h}$.

D.P.M. $(3 \mathrm{H}-\mathrm{glucose})$.

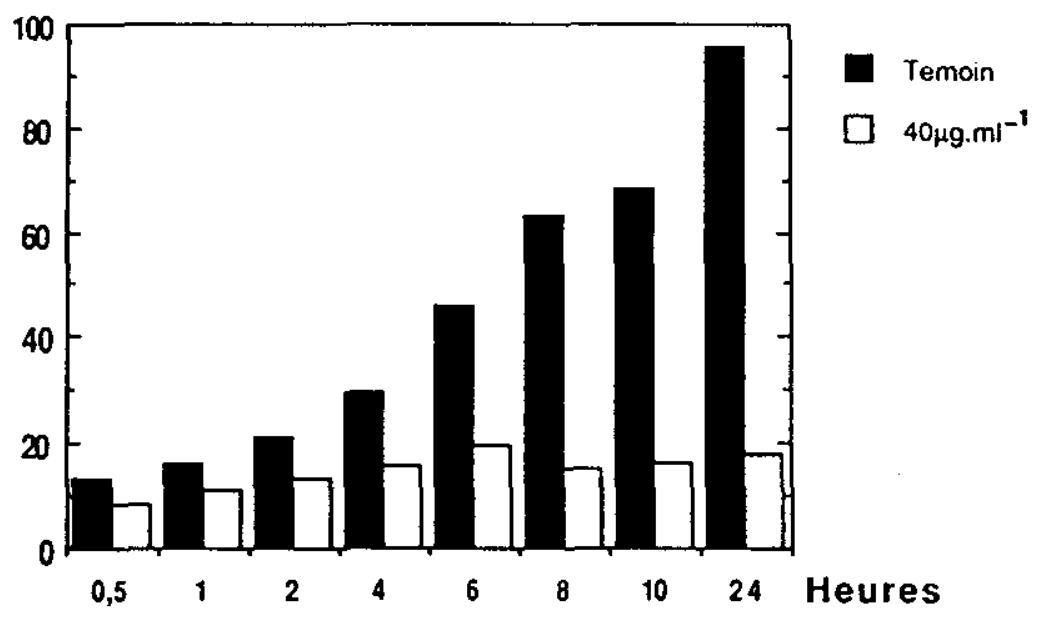

Figure 1 Effet de la gentamycine sur l'activité hétérotrophe d'une culture bactérienne. (Résultats en DPM $\times 10^{3}$ ).

Effect of gentamycin on the heterotrophic activity of a bacterial culture. (Results in DPM $\times 10^{3}$ ).

L'assimilation hétérotrophe de glucose ${ }^{-3} \mathrm{H}$ par la culture de Melosira est également réduite en présence de gentamycine (fig. 2). Cependant, les pourcentages d'inhibition sont largement inférieurs à ceux mesurés sur la culture de bactéries. En effet, le pourcentage moyen pour l'ensemble des incubations n'est que de $16,5 \%$, et il est à noter que contrairement à ce qui a été observé pour la culture de bactéries, le pourcentage d'inhibition diminue légèrement avec laugmentation de la durée d'incubation.

Enfin, il existe un effet de la gentamycine sur lactivité photosynthétique de la culture de Melosira (fig. 3). Si cet effet est faible pour des incubations de courte durée (pourcentage moyen d'inhibition pour les incubations $<4 \mathrm{~h}=$ $12,2 \%)$, en revanche l'inhibition augmente régulièrement avec la durée d'incubation (pourcentage moyen d'inhibition pour l'ensemble des incubations $=25,1 \%$ ). 
D.P.M.(3H-glucose).

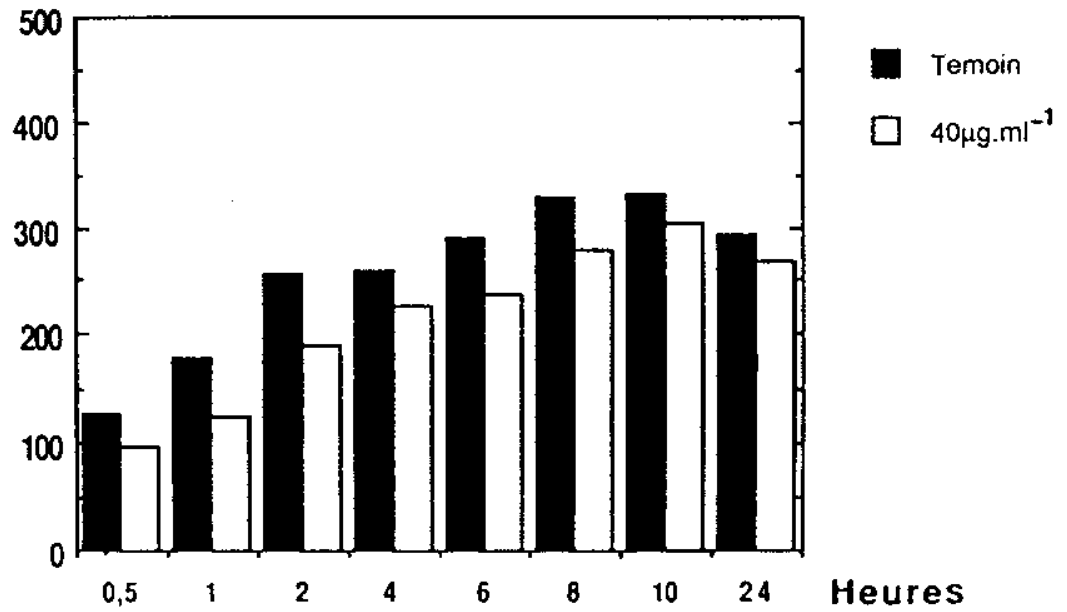

Figure 2 Effet de la gentamycine sur l'activité hétérotrophe de Melosira italica subsp. subarctica en culture. (Résultats en DPM $\times 10^{3}$ ).

Effect of gentamycin on the heterotrophic activity of Melosira italica subsp. subarctica in culture. (Results in DPM. 103).

D.P.M. $(14 C)$.

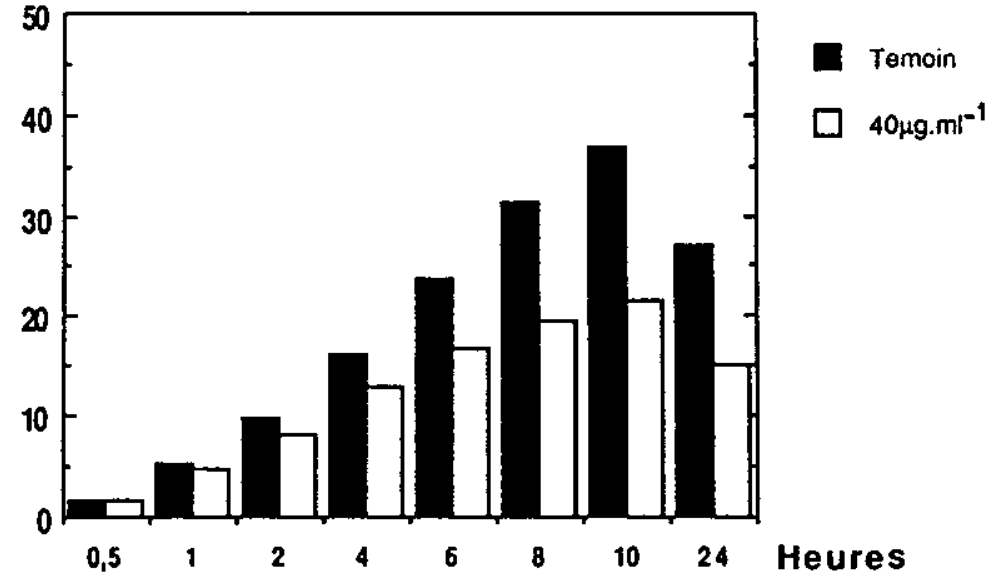

Figure 3 Effet de la gentamycine sur l'activité photosynthétique de Melosira italica subsp. subarctica en culture. (Résultats en DPM $\times 10^{3}$ ).

Effect of gentamycin on the photosynthetic activity of Melosira italica subsp. subarctica in culture. (Results in DPM. $10^{3}$ ). 


\subsection{Effets de la gentamycine sur l'allocation du carbone inorganique et de la radioactivité dans les macromolécules (culture de Melosira)}

L'incorporation par voie photosynthétique du carbone inorganique $\left({ }^{14} \mathrm{C}\right)$ dans les protéines est significativement plus faible en présence de gentamycine ( $\bar{M}=9,8 \%, \sigma=2,1 \%$ pour l'ensemble des incubations ) que dans la culture témoin ( $\bar{M}=19,4 \%, \sigma=6,0 \%$ ). Une évolution inverse est observée pour lincorporation dans les polysaccharides qui représente $35,1 \%$ $(\sigma=7,6 \%$ ) de l'incorporation totale en présence de gentamycine, mais seulement $29,7 \%(\sigma=8,0 \%)$ dans la culture témoin. Les incorporations dans les lipides et dans les composés de faible poids moléculaire ne sont pas significativement différentes avec et sans gentamycine (tableau 1).

Tableau 1 Pourcentages relatifs d'incorporation de la radioactivité issue du $\mathrm{Na}$ $\mathrm{H}^{14} \mathrm{CO}_{3}$ dans les fractions macromoléculaires et dans les composés de faible poids moléculaire (C.F.P.M.) - culture de Melosira italica -, et valeurs du test $t$ de Student (seuils de significativité : $5 \%=2,13^{*}$, $\left.1 \%=2,95^{* *}\right) . \quad \bar{M}(4 \mathrm{~h})$ : valeur moyenne pour les incubations $<4 \mathrm{~h}$; $\bar{M}(24 \mathrm{~h})$ : valeur moyenne pour l'ensemble des incubations.

Table 1 Percent incorporation of inorganic carbon $\left(\mathrm{NaH}^{14} \mathrm{CO}\right.$, into macromolécules and low molecular weight compounds (C.F.P.M.) - culture of Melosira italica -, and values of $t$ (Student's test, significance levels $\left.5 \%=2.13^{*}, 1 \% 2.95^{* *}\right) . \bar{M}(4 \mathrm{~h})$ : mean value for incubations $<4 \mathrm{~h} ; \bar{M}(24 \mathrm{~h})$ : mean value for all incubations.

\begin{tabular}{|c|c|c|c|c|c|c|c|c|c|c|}
\hline & \multicolumn{5}{|c|}{$\bar{m}(4 h)$} & \multicolumn{5}{|c|}{$\bar{M}(24 h)$} \\
\hline & $\begin{array}{l}\text { Genta } \\
\mathbf{M} \%\end{array}$ & $\begin{array}{c}\text { wcine } \\
\sigma \%\end{array}$ & $\begin{array}{l}\text { Tén } \\
\mathbf{m \%}\end{array}$ & $\begin{array}{l}\text { 201n } \\
\sigma \%\end{array}$ & Test $t$ & $\begin{array}{l}\text { Gentan } \\
\mathbf{M \%}\end{array}$ & $\begin{array}{c}\text { nycine } \\
\sigma \%\end{array}$ & $\begin{array}{l}\text { Tér } \\
\mathbf{M} \%\end{array}$ & o & Test I \\
\hline $\begin{array}{l}\text { Lipides } \\
\text { C.F.P.M. } \\
\text { Polysaccharides } \\
\text { Protéines }\end{array}$ & $\begin{array}{l}19,9 \\
30,1 \\
39,0 \\
10,8\end{array}$ & $\begin{array}{l}4,6 \\
5,3 \\
2,1 \\
2,6\end{array}$ & $\begin{array}{l}23,9 \\
30,5 \\
29,9 \\
15,6\end{array}$ & $\begin{array}{l}2,9 \\
3,8 \\
5,4 \\
1,7\end{array}$ & $\begin{array}{l}2,08 \\
0,17 \\
4,44^{* *} \\
4,36^{* *}\end{array}$ & $\begin{array}{l}26,3 \\
28,7 \\
35,1 \\
9,8\end{array}$ & $\begin{array}{l}7,7 \\
6,0 \\
7,6 \\
2,1\end{array}$ & $\begin{array}{l}27,2 \\
26,6 \\
29,7 \\
19,4\end{array}$ & $\begin{array}{l}5,4 \\
5,8 \\
8,0 \\
6,0\end{array}$ & $\begin{array}{l}0,27 \\
0,71 \\
1,39 \\
4,27^{* *}\end{array}$ \\
\hline
\end{tabular}

L'allocation de la radioactivité (glucose ${ }^{-3} \mathrm{H}$ ) dans les protéines par assimi lation hétérotrophe est, comme précédemment, significativement plus faible en présence de gentamycine ( $\bar{M}=25,6 \%, \sigma=2,9 \%$ ) que dans la culture témoin ( $\bar{M}=36,6 \%, \sigma=6,0 \%$ ). De la même façon, l'évolution inverse est observée pour l'incorporation dans les polysaccharides qui représente $41,4 \%$ $(\sigma=6,2 \%$ ) de l'incorporation totale en présence de gentamycine mais seulement $34,1 \%(\sigma=4,5 \%)$ dans la culture témoin. Bien que légèrement plus élevées en présence de gentamycine, les incorporations dans les lipides et dans les composés de faible poids moléculaire ne sont pas significativement différentes (tableau 2). 
Tableau 2 Pourcentages relatifs d'incorporation de la radioactivité issue du glucose ${ }^{-3} \mathrm{H}$ dans les fractions macromoléculaires et dans les composés de faible poids moléculaire (C.F.P.M.) - culture de Melosira italica -, et valeurs du test $t$ de Student (seuils de significativité : $5 \%=2,13^{*}, 1 \%=2,95^{* *}$ ). $\bar{M}(4 \mathrm{~h})$ : valeur moyenne pour les incubations $<4 \mathrm{~h} ; \bar{M}(24 \mathrm{~h})$ : valeur moyenne pour l'ensemble des incubations.

Table 2 Percent incorporation of inorganic carbon ( $g / u c o s e-3 H$ ) into macromolecules and low molecular weight compounds (C.F.P.M.) - culture of Melosira italica -, and values of t (Student's test, significance levels $\left.5 \%=2.13^{*}, 1 \% 2.95^{* *}\right) . \quad M(4 h)$ : mean value for incubations < $4 \mathrm{~h}$; $\bar{M}(24 \mathrm{~h})$ : mean value for all incubations.

\begin{tabular}{|c|c|c|c|c|c|c|c|c|c|c|}
\hline & \multicolumn{5}{|c|}{$\overline{\bar{M}}(4 h)$} & \multicolumn{5}{|c|}{$\bar{m}(24 h)$} \\
\hline & \multicolumn{2}{|c|}{$\begin{array}{l}\text { Gentanyclne } \\
M \% \sigma \%\end{array}$} & \multicolumn{2}{|c|}{ Témoln } & Test t & \multicolumn{2}{|c|}{$\begin{array}{l}\text { Gentamycine } \\
M \% \quad \sigma \%\end{array}$} & \multicolumn{2}{|c|}{$\begin{array}{l}\text { Témoln } \\
M \% \quad \sigma \%\end{array}$} & Test $t$ \\
\hline $\begin{array}{l}\text { Lipides } \\
\text { C.F.P.M. } \\
\text { Polysaccharides } \\
\text { Proteines }\end{array}$ & $\begin{array}{r}3,9 \\
32,2 \\
39,5 \\
24,3\end{array}$ & $\begin{array}{l}2,6 \\
0,9 \\
1,7 \\
1,2\end{array}$ & $\begin{array}{l}3,2 \\
32,3 \\
32,2 \\
32,2\end{array}$ & $\begin{array}{l}2,8 \\
6,2 \\
10,7 \\
5,3\end{array}$ & $\begin{array}{l}0,52 \\
0,05 \\
1,91 \\
4,12^{* *}\end{array}$ & $\begin{array}{c}4,7 \\
28,2 \\
41,4 \\
25,6\end{array}$ & $\begin{array}{l}2,9 \\
4,6 \\
6,2 \\
2,9\end{array}$ & $\begin{array}{c}2,8 \\
26,7 \\
34,1 \\
36,6\end{array}$ & $\begin{array}{l}1,5 \\
7,3 \\
4,5 \\
6,0\end{array}$ & $\begin{array}{l}1,65 \\
0,49 \\
2,70^{*} \\
4,66^{*}\end{array}$ \\
\hline
\end{tabular}

\subsection{Effets de la cycloheximide sur les activités hétérotrophe et photosynthétique globales des cultures d'algues et de bactéries}

Considéré comme un inhibiteur métabolique des cellules eucaryotes, la cycloheximide n'a, de tait, aucun effet significatif sur l'assimilation hétérotrophe de glucose ${ }^{-3} \mathrm{H}$ par la culture de bactéries, quelle que soit la concentration de cycloheximide considérée (fig. 4). En revanche, il est plus surprenant de constater que cet inhibiteur métabolique n'a pratiquement aucun effet sur les activités hétérotrophe et photosynthétique de la culture de Melosira, quelles que soient la concentration de cycloheximide et la durée d'incubation considérées (fig. 5 et 6 ). En effet, les pourcentages d'inhibition sont en moyenne de $3,5,1,3$ et $6,4 \%$ pour des concentrations en cycloheximide de 50,100 et $150 \mu \mathrm{g} \cdot \mathrm{mi}^{-1}$, dans le cas de l'assimilation hétérotrophe. Pour l'assimilation photosynthétique, les valeurs sont même légèrement plus élevées en présence de cycioheximide (fig. 6). 
D.P.M.(3H-glucose).

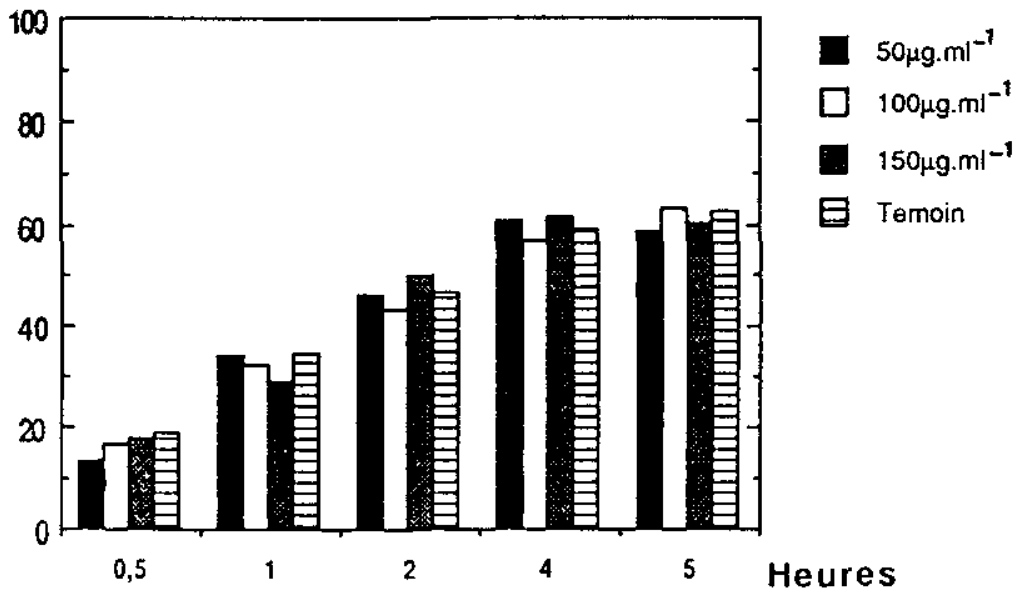

Figure 4 Effet de la cycloheximide sur l'activité hétérotrophe ơune cuiture bactérienne. (Résultats en DPM $\times 10^{3}$ ).

Effect of cycloheximide on the heterotrophic activity of a bacterial culture. (Results in DPM $\times 10^{3}$ ).

D.P.M.(3H-glucose).

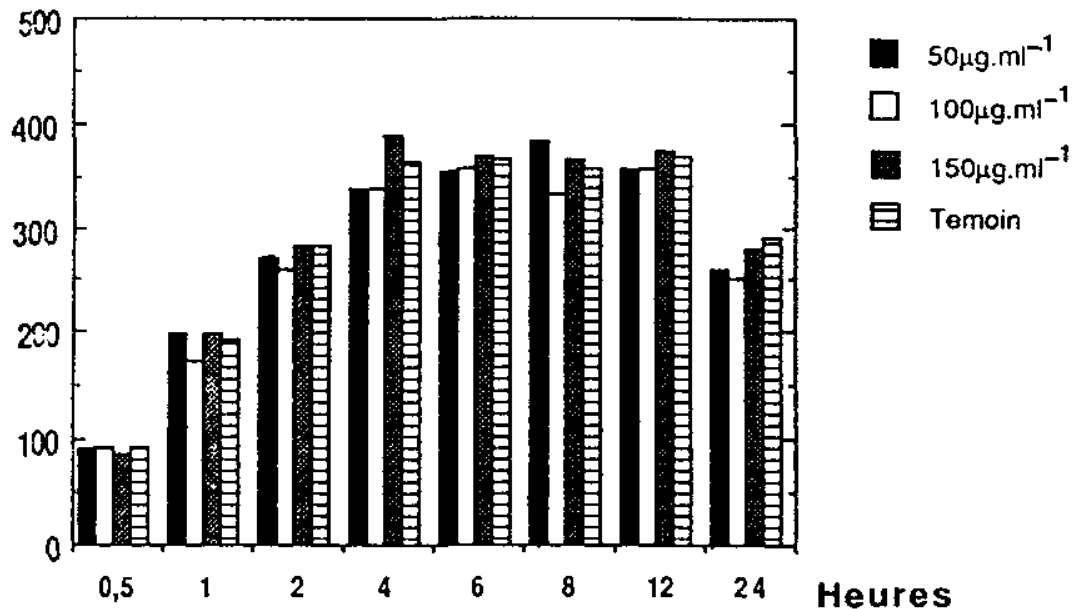

Figure 5 Effet de la cycloheximide sur l'activité hétérotrophe de Melosira italica subsp. subarctica en culture. (Résultats en DPM $\times 10^{3}$ ).

Effect of cycloheximide on the heterotrophic activity of Melosira italica subsp. subarctica in culture. (Results in DPM $\times 10^{3}$ ). 
D.P.M. (14C).

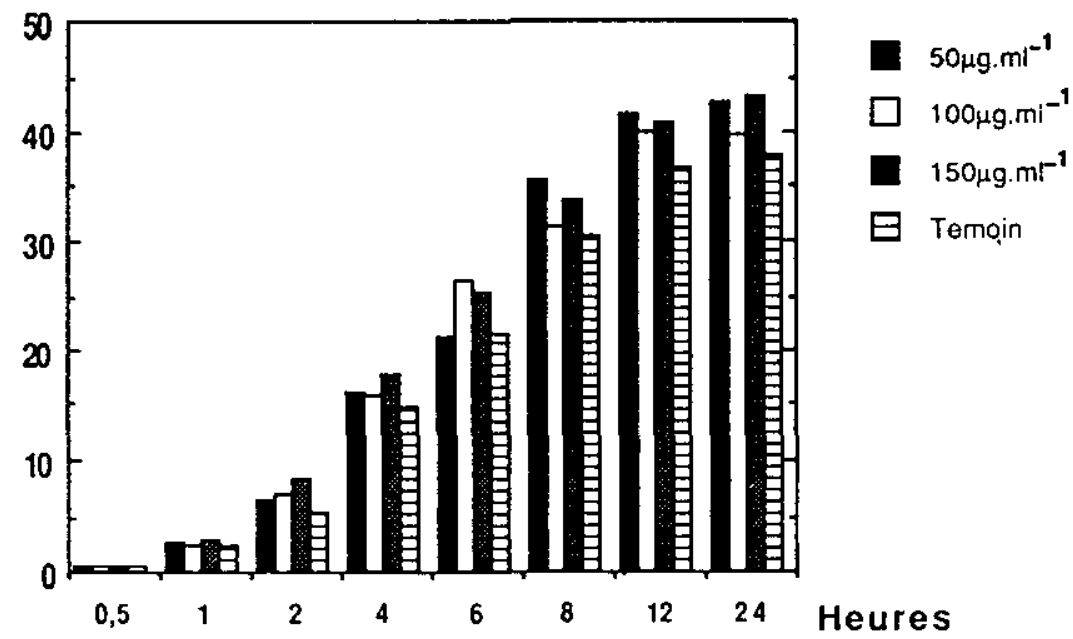

Flgure 6 Effet de la cycloheximide sur l'activité photosynthétique de Melosira italica subsp. subarctica en culture. (Résultats en DPM $\times 10^{3}$ ).

Effect of cycloheximide on the photosynthetic activity of Melosira italica subsp. subarctica in culture. (Results in DPM $\times 10^{3}$ ).

\subsection{Effets de la gentamycine sur les activités photosynthétique et hétérotrophe de différentes classes de taille microplantoniques}

Les prélèvements réalisés au lac Pavin présentent une abondance bactérienne moyenne, de fordre de $4 \times 10^{5}$ cellules. $\mathrm{ml}^{-1}$ à $5 \mathrm{~m}$ et $1,7 \times 10^{5} \mathrm{cel}$ lules. $\mathrm{mL}^{-1}$ à $50 \mathrm{~m}$. Le peuplement phytoplanctonique à $5 \mathrm{~m}$ est essentiellement composé de Chlorophycées (Chlamydomonas sp., Sphaerocystis schroeteri) et de Diatomées (Cyclotella psp., Fragilaria sp., Nitzchia sp.) pour une abondance totale de $8,5 \times 10^{5}$ cellules. $I^{-1}$. A $50 \mathrm{~m}$, la Diatomée Melosira italica subsp. subarctica est largement dominante et représente $68 \%$ du phytoplancton (abondance totale $=5,4 \times 10^{5}$ cellules. $t^{-1}$ ).

Les expériences réalisées à la profondeur $5 \mathrm{~m}$ montrent que l'activité hétérotrophe, estimée à partir de l'assimilation de glucose ${ }^{-3} \mathrm{H}$, est attribuable prioritairement à la classe $5-0,45 \mu \mathrm{m}$, puis à la classe $0,45-5 \mu \mathrm{m}$ et enfin à la classe $0,2-0,45 \mu \mathrm{m}$ qui représentent respectivement 43,39 et $18 \%$ de l'activité totale. Des résultats sensiblement identiques sont obtenus à la profondeur $50 \mathrm{~m}$ avec une importance relative encore plus grande pour la classe de taille

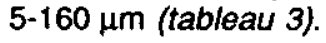


Tableau 3 Activité hétérotrophe globale (valeur moyenne pour l'ensemble des incubations), pourcentages moyens d'activité hétérotrophe associés à chacune des classes de taille planctoniques et pourcentages d'inhibition (moyenne pour l'ensemble des incubations) liés à la gentamycine dans chacune des 3 classes, pour les prélèvements 5 et $50 \mathrm{~m}$.

Table 3 Total heterotrophic activity (mean value for all incubations), mean percents of heterotrophic activity associated with each planktonic size fraction and mean percents of inhibition (for all incubations) associated with gentamycin in each of the 3 classes ( 5 and $50 \mathrm{~m}$ depths).

\begin{tabular}{|c|c|c|c|c|c|c|c|c|}
\hline & \multicolumn{4}{|c|}{$5 \mathrm{~m}$} & \multicolumn{4}{|c|}{$50 \mathrm{~m}$} \\
\hline & $\begin{array}{c}\text { Sans } \\
\text { Gentamycine } \\
\%\end{array}$ & $\begin{array}{c}\text { Avec } \\
\text { Gentamycine } \\
\%\end{array}$ & $\begin{array}{c}\% \\
\text { d'inhibition }\end{array}$ & $\begin{array}{l}\sigma \\
\%\end{array}$ & $\begin{array}{c}\text { Sans } \\
\text { Gentamycine } \\
\%\end{array}$ & $\begin{array}{c}\text { Avec } \\
\text { Gentamycine } \\
\%\end{array}$ & $\begin{array}{c}\% \\
\text { d'inhibition }\end{array}$ & $\begin{array}{l}\sigma \\
\%\end{array}$ \\
\hline $\begin{array}{c}5-160 \mu \mathrm{m} \\
0,45-5 \mu \mathrm{m} \\
0,2-0,45 \mu \mathrm{m}\end{array}$ & $\begin{array}{l}42,7 \\
39,1 \\
18,1\end{array}$ & $\begin{array}{l}64,3 \\
25,5 \\
10,2\end{array}$ & $\begin{array}{l}59,1 \\
83,5 \\
75,8\end{array}$ & $\begin{array}{r}19,4 \\
5,6 \\
37,9\end{array}$ & $\begin{array}{l}51,1 \\
35,9 \\
12,9\end{array}$ & $\begin{array}{r}80,7 \\
9,0 \\
10,3\end{array}$ & $\begin{array}{l}56,5 \\
84,8 \\
87,5\end{array}$ & $\begin{array}{l}17,1 \\
23,3 \\
20,6\end{array}$ \\
\hline $\begin{array}{c}\text { Activité globalo } \\
\mu \mathrm{O} C \cdot \mathrm{m}^{-3} \cdot \mathrm{h}^{-1} \\
\mathrm{M} \\
\sigma\end{array}$ & $\begin{array}{l}1,09 \\
0,64\end{array}$ & $\begin{array}{l}0,41 \\
0,50\end{array}$ & & & $\begin{array}{l}0,53 \\
0,16\end{array}$ & $\begin{array}{l}0,21 \\
0,20\end{array}$ & & \\
\hline
\end{tabular}


Dans les échantilions traités avec la gentamycine, l'importance relative de la classe de taille $(5-160 \mu \mathrm{m})$ est encore plus grande dans la mesure où les pourcentages d'inhibition liés à la gentamycine sont d'autant plus élevés que l'on s'adresse aux classes de petite taille $(5-0,45 \mu \mathrm{m}$ et $0,45-0,2 \mu \mathrm{m})$ (tableau 3).

Au niveau de l'assimilation photosynthétique des échantillons prélevés à $5 \mathrm{~m}, 82 \%$ de l'activité est, là encore, affecté à la classe de grande taille 5-160 $\mu \mathrm{m}$, les classes $0,45-5 \mu \mathrm{m}$ et $0,2-0,45 \mu \mathrm{m}$ ne représentant respectivement que 3 et $15 \%$ de l'activité totale. L'ajout de gentamycine n'entraîne que peu de variations quant à la contribution relative de ces trois classes de taille à l'activité photosynthétique totale (tableau 4).

Tableau 4 Assimilation photosynthétique globale (valeurs moyennes pour l'ensemble des incubations) et pourcentages moyens d'activité photosynthétique associés à chacune des classes de taille planctonique (profondeur $5 \mathrm{~m}$ ) avec et sans gentamycine.

Table 4 Total photosynthetic activity (mean value for all incubations) and mean percents of photosynthetic activity associated with each planktonic size fraction (5 m depth) with and without gentamycin.

\begin{tabular}{|ccc|}
\hline & $\begin{array}{c}\text { Sans gentamycine } \\
\%\end{array}$ & $\begin{array}{c}\text { Avec gentamycine } \\
\%\end{array}$ \\
\hline $5-160 \mu \mathrm{m}$ & 82,5 & 80,9 \\
$0,45-5 \mu \mathrm{m}$ & 3,0 & 2,9 \\
$0,2-0,45 \mu \mathrm{m}$ & 14,5 & 16,2 \\
Activité globale & & \\
mg C.m-3.h $\mathrm{h}^{-1}$ & & \\
$M$ & 2,18 & 1,76 \\
$\sigma$ & 1,63 & 1,46 \\
\hline
\end{tabular}

\subsection{Effets de la gentamycine sur l'allocation du carbone inorganique et de la radioactivité dans les macromolécules (échantillons naturels, classe de taille 5-160 $\mu \mathrm{m}$ )}

A $5 \mathrm{~m}$, on constate que l'incorporation du carbone inorganique par voie photosynthétique est significativement plus élevée dans les composés de faible poids moléculaire en présence de gentamycine (tableau 5). Cette augmentation se fait au détriment de l'incorporation dans les polysaccharides, les protéines et les lipides, mais les différences en pourcentage d'incorporation sont peu marquées et non significatives (tableau 5). 
Tableau 5 Pourcentages relatifs d'incorporation (valeur's moyennes pour l'ensemble des incubations) du $\mathrm{NaH}^{14} \mathrm{CO}_{3}$ dans les fractions macromoléculaires et dans les composés de faible poids moléculaire (C.F.P.M.) (profondeur $5 \mathrm{~m}$ ) et valeurs du test $t$ de Student (seuils de significativité : $\left.5 \%=2,13^{*}, 1 \%=2,95^{* *}\right)$.

Table 5 Percent incorporation of inorganic carbon $\left(\mathrm{NaH}^{14} \mathrm{CO}_{3}\right)$ into macromolecules and low molecular weight compounds (C.F.P.M) (mean value for all incubations) ( $5 \mathrm{~m}$ depth), and values of $t$ (Student's test, significicance levels $\left.5 \%=2.13^{*}, 1 \%=2.92^{*}\right)$.

\begin{tabular}{|c|c|c|c|c|c|}
\hline & \multicolumn{2}{|c|}{ Sans gentamyclne } & \multicolumn{2}{|c|}{ Avec gentamycine } & \multirow[b]{2}{*}{ Test 1} \\
\hline & 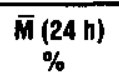 & $\begin{array}{l}\sigma \\
\%\end{array}$ & $\begin{array}{c}\bar{m}(24 \mathrm{~h}) \\
\%\end{array}$ & $\begin{array}{l}\sigma \\
\%\end{array}$ & \\
\hline Lipides & 11,7 & 4,4 & 8,2 & 1,8 & 2,08 \\
\hline C.F.P.M. & 19,8 & 5,3 & 28,1 & 6.4 & $2,82^{*}$ \\
\hline Polysaccharides & 47,2 & 8,8 & 43,8 & 5,8 & 0,91 \\
\hline Protéines & 21,2 & 6,4 & 19,9 & 9,8 & 0,31 \\
\hline
\end{tabular}

Après assimilation hétérotrophe de glucose ${ }^{-3} \mathrm{H}$, l'allocation de la radioactivité dans les composés de faible poids moléculaire est pratiquement deux fois plus élevée en présence de gentamycine, que l'on considère les échantillons prélevés à 5 ou à $50 \mathrm{~m}$ (tableau 6). Cette augmentation se fait au détriment essentiellement de l'incorporation dans les polysaccharides et dans les protéines.

\section{4- DISCUSSION}

Au terme de cette étude, il apparaît que la gentamycine réduit de façon significative mais non totale (pourcentage d'inhibition moyen $=66,7 \%$ ) l'assimilation hétérotrophe de glucose ${ }^{-3} \mathrm{H}$ effectuée par une culture de bactéries. L'efficacité de la gentamycine est, par ailleurs, liée à la durée d'incubation puisque le pourcentage d'inhibition atteint en moyenne $74,8 \%$ pour les incubations dont la durée est comprise entre 4 et 24 heures. L'activité hétérotrophe d'une culture d'algues semble également affectée par la présence de gentamycine mais les pourcentages d'inhibition sont nettement moins élevés dans la mesure où ils n'atteignent, en moyenne pour l'ensemble des incubations, que $16.5 \%$. Enfin, nous avons pu montrer que cette substance considérée essentiellement comme antibactérienne affecte également l'activité photosynthétique algale. Si le pourcentage d'inhibition $(12,2 \%)$ est acceptable pour des incubations de courte durée $(<4 \mathrm{~h})$, en revanche, il devient un obstacle à son utilisation pour les incubations de longue durée puisque ce pourcentage d'inhibition est en moyenne de $38 \%$ pour les incubations comprises entre 4 et 24 heures. 
Tableau 6 Pourcentages relatifs d'incorporation (valeurs moyennes pour l'ensemble des incubations) de la radioactivité issue du glucose ${ }^{-3} \mathrm{H}$ dans les fractions macromoléculaires et dans les composés de faible poids moléculaire (C.F.P.M.) pour les prélèvements 5 et $50 \mathrm{~m}$, et valeurs du test t de Student (seuils de significativité : $5 \%=2,13^{*}, 1 \%=2,95^{\star *}$ ).

Table 6 Percent incorporation of radioactivity after incorporation of glucose ${ }^{-3} \mathrm{H}$ into macromolecules and low molecular weight compounds (C.F.P.M.) at 5 and $50 \mathrm{~m}$ depths, and values of $t$ (Student's tests, significance levels $5 \%=2,13^{*}, 1$ $\left.\%=2,95^{* *}\right)$.

\begin{tabular}{|c|c|c|c|c|c|c|c|c|c|c|}
\hline & \multicolumn{5}{|c|}{$5 \mathrm{~m}$} & \multicolumn{5}{|c|}{$50 \mathrm{~m}$} \\
\hline & $\begin{array}{c}\text { Sans gent } \\
M(24 h) \\
\%\end{array}$ & $\begin{array}{c}\text { mycine } \\
\% \\
\%\end{array}$ & $\begin{array}{c}\text { Avec gen } \\
M(24 \mathrm{~h}) \\
\%\end{array}$ & $\begin{array}{c}\text { mycine } \\
\sigma \\
\%\end{array}$ & Test $t$ & $\begin{array}{c}\text { Sans genta } \\
M(24 h) \\
\%\end{array}$ & $\begin{array}{c}\text { ycing } \\
\sigma \\
\%\end{array}$ & $\begin{array}{c}\text { Avec gen } \\
M(24 h) \\
\%\end{array}$ & $\begin{array}{c}\text { ycine } \\
\sigma \\
\%\end{array}$ & Test t \\
\hline $\begin{array}{l}\text { Lipides } \\
\text { C.F.P.M. } \\
\text { Poluysaccharides } \\
\text { Protéines }\end{array}$ & $\begin{array}{r}2,9 \\
15,1 \\
58,3 \\
23,7\end{array}$ & $\begin{array}{l}0,7 \\
4,0 \\
6,7 \\
6,4\end{array}$ & $\begin{array}{r}3,3 \\
28,2 \\
47,2 \\
21,2\end{array}$ & $\begin{array}{l}0,4 \\
4,6 \\
4,8 \\
6,1\end{array}$ & $\begin{array}{l}1,43 \\
6,09^{* *} \\
3,81^{* *} \\
0,80\end{array}$ & $\begin{array}{r}2,9 \\
17,5 \\
58,4 \\
21,0\end{array}$ & $\begin{array}{r}0,8 \\
10,2 \\
8,1 \\
4,9\end{array}$ & $\begin{array}{r}6,3 \\
48,6 \\
34,8 \\
10,3\end{array}$ & $\begin{array}{r}1,9 \\
16,8 \\
11,7 \\
5,4\end{array}$ & $\begin{array}{l}4,66^{* *} \\
4,47^{* *} \\
4,69^{* *} \\
4,15^{* *}\end{array}$ \\
\hline
\end{tabular}


Des résultats sensiblement analogues sont rapportés quant à l'efficacité et la spécificité de l'action de la gentamycine par différents auteurs (BERMAN, 1975 ; CHROST, 1978, 1984 ; ITTURIAGA et ZSOLNAY, 1981 ; FEUILLADE ot al., 1988). En effet, ces auteurs montrent que l'inhibition par la gentamycine n'est généralement pas totale et s'avère dépendante de la durée d'incubation. De plus, cette substance antibiotique supposée agir sur les cellules procaryotes, est susceptible d'affecter le fonctionnement des organites cellulaires (plastes, mitochondries) d'eucaryotes (GRAY et DOOLTTLLE, 1982 ; U et DICKIE, 1985).

En revanche, aucune étude n'a, à notre connaissance, considéré les effets de cet inhibiteur métabolique sur l'allocation des marqueurs radioactifs dans la synthèse des macromolécules. A partir des cultures d'algues et de bactéries, ou à partir des échantillons prélevés en milieu naturel, nous avons pu constater que la présence de gentamycine modifie l'allocation des marqueurs radioactifs dans les macromolécules et dans les composés de faible poids moléculaire. En culture algale, le pourcentage d'incorporation dans les polysaccharides est plus élevé en présence de gentamycine, augmentation qui se fait au détriment de l'incorporation dans les protéines. A partir des échantillons prélevés en milieu naturel l'incorporation dans les protéines est encore affectée, de même que l'incorporation dans les polysaccharides, au profit de l'incorporation dans les composés de faible poids moléculaire. Ces résultats prétiminaires semblent cohérents avec le mode d'action de la gentamycine qui agit au niveau de la synthèse protéique.

Considéré comme un inhibiteur métabolique des eucaryotes agissant au niveau de la fonction des ribosomes 805 , remploi de la cycloheximide à différentes concentrations s'est révélé sans aucun effet significatí sur les activités photosynthétique et hétérotrophe d'une culture de Melosira italica puisque les pourcentages d'inhibition étaient compris entre 0 et $6,5 \%$. Exception faite de l'étude de $\mathrm{LI}$ et DICKIE (1985) qui a montré que la cycloheximide n'a aucune influence sur le nanoplancton mais affecte seulement la fixation de $\mathrm{CO}_{2}$ par le microplancton, les effets de cet inhibiteur sur l'activité du phytoplancton sont largement méconnus (SANDERS et PORTER, 1986).

A partir des échantillons prélevés en milieu naturel, l'emploi de la gentamycine a permis de réduire l'interférence bactérienne dans les mesures d'activité hétérotrophe algale. Les pourcentages d'inhition liée à la présence de gentamycine sont, en effet, nettement plus élevés dans les classes de petite taille $(5-0,45 \mu \mathrm{m}$ et $0,45-0,2 \mu \mathrm{m})$ où prédomine la biomasse bactérienne par rapport a la biomasse phytoplanctonique. Inversement, dans la classe de taille (5$160 \mu \mathrm{m})$, la biomasse microplanctonique est essentiellement de nature algale dans la mesure où les bactéries fixées susceptibles d'être retenues dans cette fraction de taille ne représentent que $6 \%$ de l'abondance bactérienne totale (AMBLARD et al., en préparation). Cela conduit à penser qu'une part importante de l'activité hétérotrophe mesurée pour la classe de taille 5-160 $\mu \mathrm{m}$ (de l'ordre de 0,24 à $0,46 \mu \mathrm{g} \mathrm{C} \cdot \mathrm{m}^{-3} \cdot \mathrm{h}^{-1}$, tableau 3) est attribuable à l'activité hétérotrophe algale.

En conclusion, il apparaît que si l'utilisation de la cycloheximide n'a aucun intérêt pour la séparation des activités hétérotrophes, bactérienne et algale, en revanche, la gentamycine permet une réduction significative mais non totale 
de l'interférence bactérienne, sans entraîner d'effets secondaires trop importants si la durée d'incubation est inférieure à 4 heures. Associé à un fractionnement par classe de taille, l'emploi de la gentamycine nous a ainsi permis de supporter l'hypothèse d'une activité hétérotrophe algale non négligeable en milieu lacustre. Cependant, seules des études microautoradiographiques permettent d'identifier précisément les microorganismes responsables de l'assimilation d'un composé organique (BOURDIER et al., 1989 ; AMBLARD et al,, 1990 ; AMBLARD, sous presse).

\section{REMERCIEMENTS}

Cette étude a été partiellement financée par le Centre National d'Etudes Spatiales (contrat $n^{\circ}$ 90/CNES/248).

\section{RÉFÉRENCES BIBLIOGRAPHIQUES}

AMBLARD C. Activité hétérotrophe des microalgues et des cyanobactéries vis-à-vis du carbone : implications ecophysiologiques. Ann. Biol., sous presse.

AMBLARD C., COUTURE P., BOURDIER G., 1990. Effects of a pulp and paper mill et fluent on the structure and metabolism of periphytic algae in experimental streams. Aquat. Toxicol., 18, 137-162.

BERMAN T., 1975. Size fractionation of natural aquatic populations associated with autotrophic and heterotrophic carbon uptake. Mar. Biol. (Bert), 33, 215-220.

BIRD D.F., KALFF J., 1986. Bacterial grazing by planktonic lake algae. Science Wash. D.C., 231, 493-495.

BOURDIER G., BOHATIER \&. FEUILLADE M., FEUILLADE J., 1989. Amino acid incorporation by a natural population of Oscillatoria rubescens. A microautoradiographic study. FEMS Microbiol. Ecol., 62, 185-190.

CHROST R.J., 1978. The estimation of extracellular release by phytoplankton and hete rotrophic activity of aquatic bacteria. Acta Microbiol. Pol., 27, 139-146.

CHROST R.J., 1984. Use of ${ }^{14} \mathrm{C}$-dissolved organic carton (RDOC) released by algae as a reatistic tracer of heterotrophic activity measurements for aquatic bacteria. Arch. Hydrobiol. Beih. Ergehn. Limnol., 19, 207214.

DROOP M.R., 1974. Heterotrophy of carbon. In : Stewart, W.D.P. Ed. Physiology and Biochemistry of algae, University of California Press, Berkeley.

ELLIS B.K., STANFORD J.A., 1982. Comparative photoheterotrophy, chemoheterotrophy and photolithotrophy in a eutrophic reservoir and an oligotrophic lake, Limnol. Oceanorgr., 27, 440-454.

FEUILLADE M., DUFOUR Ph., FEUILLADE J., 1988. Organic carton release by phytoplankton and bacterial reassimilation. Sctweitz. Z. Hydrol., 50, 115-135.

FUHRMAN J.A., McMANUS G.B., 1984. Do bacteria-sized marine eucaryotes consume significant bacterial production ? Science, 224, 1257-1260.

GRAY M.W., DOOLITTLE W.F., 1982. Has the endosymbiont hypothesis been proven? Microbiol. Rev., 46, 1-42.

HELLEBUST J.A., 1970. The uptake and utilization of organic substances by marine phytoplankters. In Hood, D.W. Symposium 
on Organic Matter in natural Waters, Univ. of Alaska, Fairbanks, Inst. Mar. Sci. Occ. Publ., $n^{\circ} 1,223-256$.

HELLEBUST J.A., LEWIN J., 1977. Heterotrophic nutrition. In Werner, D. Ed. Biology of Diatoms, Univ. of California Press, Berkeley, 169-197.

HOBBIE J.E., DALEY R.J., JASPER S., 1977. Use of nucleopore filters for counting bacteria by fluorescence microscopy, Appl. Environ. Microbiol., 33, 1225-1228.

HOPPE H.G., 1976. Determination and properties of actively metabolizing heterotrophic bacteria in the sea, investigated by means of microautoradiography. Mar. Biol., 36. 291-302.

ITURRIAGA R., ZSOLNAY A., 1981. Differentiation between auto- and heterotrophic activity: Problems in the use size fractionation and antibiotics, Bot. Mar., 24, 399-404.

LANCELOT C., MATHOT S., 1985. Biochemical fractionation of primary production by phytoplankton in Belgian coastaf waters ouring short- and long term incubations with ${ }^{14} \mathrm{C}$-bicarbonate, Mar. Biol., 86, 227-232.

LEGENDRE L., WATT W.D., 1971-1972. On a rapid technique for plankton enumeration. Ann. Inst. Oceanogr., Paris, XLVIII, \$73177.

LEWIN J., HELLEBUST, J.A., 1976. Heterotrophic nutrition of the marine pennate diatom Nitzschia angularis var. affinis. Mar. Biol. (Bert.). 36. 313-320.

LI W.K.W., DICKIE P.M., 1985. Metabolic inhibition of size-fractionaled marine plankton radiolabelied with aminoacids, glucose, bicarbonate and phosphate in the light and dark, Microb. Ecol., 11, 11-24.

MC KINLEY K.R., 1977. Light-mediated uptake of ${ }^{3} \mathrm{H}$-glucose in a small hardwater lake, Ecologr, 58, 1356-1365.

MC KINLEY, K.R. WETZEL R.G., 1979. Photolithotrophy, photoheterotrophy and chemoheterotrophy : Patterns of ressource utilization on an annual and a diurnal basis within a pelagic microbial community. Microbiol. Ecol., 5, 1-15.

MOLL R., 1984. Heterotrophy by phytoplankton and bacteria in lake Michigan. Verh. Internat. Verein. Limnol, 22, 431-434.
MUNRO A.L.S., BROCK T.D., 1968. Distribution between bacterial and algal utilization of soluble substances in the sea, J. Gen. Microbiol., 51, 35-42.

NEILSON A.H., LEWIN R.A., 1974. The uptake and utilization of organic carbon by algae : an, assay in comparative biochemistry, Phycologia, 13, 227-264.

NEWELL S.Y., SHERR B.F., SHERR E.B., FALLON R.F.D., 1983. Bacterial response to presence of eukaryotic inhibitors in water from a coastal marine environment. Mar. Environ. Res., 10, 147-157.

PAERL H.W., 1988. Growth and reproductive strategies of freshwater blue-green algae (Cyanobacteria). In Growth and Reproductive Strategies of Freshwater Phytoplankton, Sandgren C.O. Ed., 261-315.

RIVKIN R.B., PUTT M., 1987. Heterotrophy and photoheterotrophy by Antarctic microalgae light-dependent incorporation of amino acids and glucose, J. Phycol., 23, 442-452.

SANDERS R.W., PORTER K.G., 1986. Use of metabolic inhibitors to estimate protozooplankton grazing and bacterial production in a monomictic eutrophic lake with an anaero. bic hypolimnion. Appl. Environ. Microbiol., 101-107.

SHELDON R.W., SUTCLIFFE W.H., 1969. Retention of marine particles by screens and filters. Limnol. Oceanogr., 14, 441-444.

SHELDON R.W., 1972. Size separation of marine seston by membrane and glass fiber filters. Limnol. Oceanogr., 17, 494-498.

STANIER R.Y., 1973. Autotrophy and heterotrophy in cellular blue-green algae. In N.G. Carr \& B.A. Whitton ED. The biology of blue-green algae. Univ. Calif. Press, Berkeley.

UTERMOHL H., 1958. Zur Vervollkommung der quantitativen Phytoplankton-Methodik. Mitt. Inem. Ver. Limnol., 9, 38 p.

WETZEL R.G., 1983. Limnology. Saunders College, New York (USA), second edition, 767 pp.

WRIGHT R.T., HOBBIE J.E., 1966. The use of glucose and acetate by bacteria and atgae in aquatic ecosystems, Ecology, 47, 447. 464. 